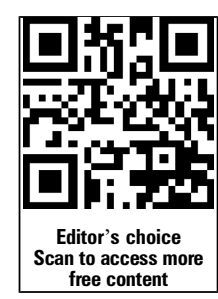

For numbered affiliations see end of article.

\section{Correspondence to} Dr José Ramón López Mínguez, Adelardo Covarsí n¹; 6. ${ }^{\circ}$ D. Badajoz 06005, Spain;

lopez-minguez@hotmail.com

Received 9 June 2014 Revised 25 November 2014 Accepted 15 December 2014 Published Online First 8 January 2015

\section{CrossMark}

To cite: López Mínguez JR, Nogales Asensio JM, Gragera JE, et al. Heart 2015;101:877-883.

\title{
Two-year clinical outcome from the Iberian registry patients after left atrial appendage closure
}

\author{
José Ramón López Mínguez, ${ }^{1}$ Juan Manuel Nogales Asensio, ${ }^{1}$ \\ Javier Elduayen Gragera, ${ }^{1}$ Marco Costa, ${ }^{2}$ Ignacio Cruz González, ${ }^{3}$ \\ Federico Gimeno de Carlos, ${ }^{4}$ José Antonio Fernández Díaz, ${ }^{5}$ Victoria Martín Yuste, ${ }^{6}$ \\ Raúl Moreno González, ${ }^{7}$ Antonio Domínguez-Franco, ${ }^{8}$ Amparo Benedicto Buendía, ${ }^{9}$ \\ Jesús Herrero Garibi, ${ }^{10}$ Felipe Hernández Hernández, ${ }^{11}$ Vasco Gama Ribeiro ${ }^{12}$
}

\section{ABSTRACT}

Aims The aim of this study was to observe the percentage of thromboembolic and haemorrhagic events over a 2-year follow-up in patients with non-valvular atrial fibrillation (NVAF) undergoing closure of the left atrial appendage (LAA) with an occlusion device. Observed events and $\mathrm{CHADS}_{2}$ (congestive heart failure, hypertension, age, diabetes, stroke history), $\mathrm{CHA}_{2} \mathrm{DS}_{2^{-}}$ VASc (also adding: vascular disease and sex) and HASBLED (hypertension, abnormal liver/renal function, stroke history, bleeding predisposition, labile international normalised ratios, elderly, drugs/alcohol use)-predicted events were compared.

Methods LAA closure with an occlusion device was performed in 167 NVAF patients contraindicated for oral anticoagulants and recruited from 12 hospitals between 2009 and 2013. At least two transoesophageal echocardiograms were performed in the first 6 months postimplantation. Antithrombotics included clopidogrel and aspirin. Patients were monitored for death, stroke, major and relevant bleeding and hospitalisation for concomitant conditions. Mean age was 74.68 \pm 8.58 , median follow-up was 24 months, 5.38\% had intraoperative complications and implantation was successful in $94.6 \%$ of subjects. Mortality during followup was $10.8 \%$, mostly $(9.5 \%)$ non-cardiac related. Bleeding occurred in $10.1 \%$ of subjects, $5.7 \%$ major and $4.4 \%$ minor though relevant, and $4.4 \%$ suffered stroke. Major bleeding and stroke/transient ischaemic attack events within 2 years (annual event rates, 290 patients/year) were less frequent than expected from $\mathrm{CHADS}_{2}$ (2.4\% vs 9.6\%), $\mathrm{CHA}_{2} \mathrm{DS}_{2}$-VASC (2.4\% vs $8.3 \%)$ and HAS-BLED (3.1\% vs $6.6 \%)$ risk scores $(p<0.001, p=0.003, p=0.047$, respectively).

Conclusions LAA closure with an occlusion device in patients contraindicated for oral anticoagulants is a therapeutic option associated with fewer thromboembolic and haemorrhagic events than expected from risk scores, particularly in the second year postimplantation.

\section{INTRODUCTION}

In recent years, four new oral anticoagulants (OACs) have shown advantages over warfarin in the prevention of thromboembolic complications in non-valvular atrial fibrillation (NVAF). Although their main advantages (reduction of intracranial haemorrhage and no international normalised ratio
(INR) monitoring) are interesting, the risks inherent to their anticoagulant action remain unchanged, and they significantly increase the cost of surgery. The relative reduction in the number of events is striking but less relevant in absolute terms. ${ }^{1}$

Closure of the left atrial appendage (LAA), the site of over $90 \%$ of thrombi in these patients, has initially been shown to reduce incidence of intracranial haemorrhage. It is at least as effective as warfarin in reducing thromboembolic events, ${ }^{2}$ but might be superior to warfarin in longer follow-up periods. ${ }^{3}$ LAA occlusion is now starting to appear in treatment guidelines.

The aim of this study was to observe the percentage of thromboembolic and haemorrhagic events over a 2-year follow-up in patients with NVAF undergoing LAA closure with an occlusion device, comparing observed events versus $\mathrm{CHADS}_{2}$ (congestive heart failure, hypertension, age, diabetes, stroke history), $\mathrm{CHA}_{2} \mathrm{DS}_{2}$-VASc (also adding vascular disease and sex) and HAS-BLED (hypertension, abnormal liver/renal function, stroke history, bleeding predisposition, labile INRs, elderly, drugs/ alcohol use)-predicted events. ${ }^{6-9}$

\section{METHODS}

The working method used in this and subsequent studies was approved by the independent ethics committees of contributing hospitals, and all patients provided informed consent for this study. All procedures comply with the Declaration of Helsinki. The authors' institutions approved the data analysis.

\section{Patients}

Closure of LAA with an ACP device (Amplatzer Cardiac Plug, St Jude Medical, Minneapolis, Minnesota, USA) was performed in 167 patients with NVAF recruited from 12 hospitals between March 2009 and early 2013. Inclusion criteria were one or more of the following conditions: serious haemorrhage during acenocoumarol therapy, prior disease or clinical event that contraindicated OACs or repeated failure to adequately control INR, and haematologist indication to suspend acenocoumarol.

\section{Implantation procedure}

All patients underwent a transoesophageal echocardiogram (TOE) 24-48 $\mathrm{h}$ prior to the procedure to 
rule out the presence of LAA thrombi. One hour prior to procedure, patients were given a wide-spectrum antibiotic (cephalosporin), and the procedure was performed under general anaesthetic. Following transseptal puncture, patients were administered $100 \mathrm{U} / \mathrm{kg}$ heparin. Selective angiography of the LAA was performed with a volume similar to that of a left coronary artery, and generally in right anterior oblique (RAO) $\left(20^{\circ}-20^{\circ}\right)$ caudal and also RAO $\left(30^{\circ}-10^{\circ}\right)$ cranial views. The calibration reference point was a $23 \mathrm{~mm}$ radio-opaque ball on the midaxillary line. 2D TOE measurements were taken during the procedure. A preliminary $40^{\circ}-135^{\circ}$ scan with the probe in mid-oesophageal position was performed to obtain both ostium diameters: minor (usually between $45^{\circ}$ and $70^{\circ}$ ) and major (at approximately $135^{\circ}$ ). The device was chosen according to the official St Jude Medical scoring table, which is based on the measurement ranges of the ostium of the LAA. As a general rule, the size of the device was based on the length of the longest axis of the TOE, usually the superoinferior axis. These measurements were similar to those obtained by angiography in the right caudal projection. In the case of borderline measurements, the largest size was selected. The same operator carried out the procedure at each hospital, and in all cases transseptal puncture was uncomplicated; these factors, therefore, did not affect the study variables.

\section{Postimplantation treatment and follow-up}

At the coordinating hospital, follow-up TOE was performed 1 day after intervention, and then at $1,3,6$ and 12 months to monitor placement of the device, the presence or absence of interatrial shunting and absence of flow to the LAA, focusing above all on the possible presence of thrombus on the device. In the contributing hospitals, at least two follow-up visits were performed during the 6 months postimplantation. Following implantation, a loading dose $(600 \mathrm{mg})$ of clopidogrel was administered, and treatment was started with $300 \mathrm{mg}$ aspirin (ASA) on the first day and $100 \mathrm{mg}$ daily thereafter. Clopidogrel was maintained for 3-6 months, barring haemorrhagic complications, and ASA for 6-12 months. If thrombus occurred, subcutaneous enoxaparin in a therapeutic dose was added for 2 weeks, clopidogrel was prolonged and the TOE was repeated to check for disappearance. If the result was negative, the decision to prolong the treatment for another week or hospitalise the patient and begin treatment with intravenous heparin was evaluated.

\section{Definition of outcomes}

Implantation was successful when the following criteria were met: (a) appropriate distance between the body and the outer disc; that is, the body of the device in the neck of the LAA and the disc covering the ostium, with both standard angiographic views (cranial RAO and caudal RAO) or the short-axis view showing a clear separation between them; (b) lightly compressed body or lobe (tyre shape) without the 'raspberry' effect indicative of excessive compression; (c) absence of flow between the left atrium and the LAA over the device or, failing that, $<3 \mathrm{~mm}$ on a colour Doppler ultrasound; and (d) proof of firm anchorage to the LAA using the tug test.

The main events were death, stroke, serious and relevant haemorrhage, and hospitalisation for concomitant conditions, monitored by means of scheduled visits and telephone calls. The International Society on Thrombosis and Haemostasis definition was used to define major bleeding: fatal bleeding, and/or symptomatic bleeding in a critical area or organ, such as intracranial, intraspinal, intraocular, retroperitoneal, intra-articular or pericardial, or intramuscular with compartment syndrome, and/or bleeding causing a fall in haemoglobin level of $20 \mathrm{~g} / \mathrm{L}$ $(1.24 \mathrm{mmol} / \mathrm{L})$ or more, or leading to transfusion of two or more units of whole blood or red cells. ${ }^{10}$ Minor but relevant bleeding was defined according to the Academic Research Consortium ${ }^{11}$ guidelines as any bleeding not meeting major criteria but important enough for the patient or the clinician to merit discontinuation of antithrombotic therapy, albeit temporarily: (1) The patient does not visit the doctor but can suspend antithrombotic therapy, for example, haematoma, epistaxis, haemorrhoidal bleeding, and so on and (2) The patient visits the doctor and action is needed, for example, suspension of antithrombotic therapy, diagnostic tests and hospitalisation.

\section{Statistical analysis}

Continuous variables are expressed as mean \pm SD or median (25th-75th percentiles), depending on distribution of data. Categorical variables were compared using $\chi^{2}$ or Fisher's exact test, and numerical variables were analysed using the Student's $t$ test or the Wilcoxon test. The observed incidence of events (number of events during the follow-up period divided by the number of patients per year of follow-up) was calculated per patient and year of follow-up (number of patients at the beginning of the follow-up period multiplied by the mean time of follow-up of those patients expressed in years).

The expected incidence of events in the sample was calculated as the mean of the individual risk of each patient. Each patient was assigned an individual risk according to a score of bleeding and ictus risk depending on his or her $\mathrm{CHADS}_{2}$ and HAS-BLED score, as indicated in the work by Friberg and colleagues. ${ }^{9}$

Annual risk of bleeding or stroke was based on each patient's $\mathrm{CHADS}_{2}$ and HAS-BLED score. Observed and expected rates of thromboembolic and bleeding events were compared using binomial tests. Event-free survival was analysed using the KaplanMeier method. All data were analysed using SPSS V.19.0.

\section{RESULTS}

\section{Characteristics of the population}

Table 1 shows the baseline characteristics of the 167 patients. None were eligible for randomised studies in OAC since these were contraindicated for the reasons listed in table 1 . The main indications for LAA occlusion were OAC contraindication or complications, mostly gastrointestinal $(30.5 \%)$ and neurological (22.8\%). Mean age was 74.68 \pm 8.58 . Median $\mathrm{CHADS}_{2}$, $\mathrm{CHA}_{2} \mathrm{DS}_{2}$-VASc and HAS-BLED scores and 25 th-75th percentile were, respectively, $3(2-4), 4(3-6)$ and $3(3-4)$.

Mean follow-up was 24 months (mean $22 \pm 8.3$ months), giving a follow-up rate of 290 patients per year. The intraprocedure complication rate was $5.38 \%$, with $2.99 \%$ being central and $2.39 \%$ vascular due to a punctured artery resulting in arteriovenous fistula despite prolonged compression. There was one case of migration during the procedure just after the release of the device that was successfully captured and replaced by a larger device; two cases of cardiac tamponade that were resolved with pericardial puncture; and two intraoperative transient ischaemic attacks (TIAs) that left no sequelae.

Median device size was 24 (25th-75th percentile 22-25). For size 16 , the percentage of use was $6.3 \%$; for size $18,6.3 \%$; for size 20, $11.4 \%$; for size $22,22.2 \%$; for size $24,27.8 \%$; for size $26,16.5 \%$, for size $28,7 \%$ and for size $30,2.5 \%$. The rate of successful implantation was $94.6 \%$.

Table 2 shows the outcomes of raw clinical events (data not adjusted for patient/year) over the 2-year follow-up in 158 patients with successful implants. Mortality was $10.8 \%$, mostly (9.5\%) non-cardiac related. Bleeding was observed in $10.1 \%$ of 
Table 1 Baseline and procedure-associated characteristics $(n=167)$

\begin{tabular}{|c|c|}
\hline $\begin{array}{l}\text { Age (in years) } \\
\geq 75 \text { years: } 84(53.2 \%) ; \geq 78 \text { years: } 63(39.9 \%)\end{array}$ & $74.68 \pm 8.58$ \\
\hline Men & $102(61.1 \%)$ \\
\hline $\mathrm{CHADS}_{2}$ & $3(2-4)$ \\
\hline $\mathrm{CHA}_{2} \mathrm{DS}_{2}$-VASC & $4(3-6)$ \\
\hline HAS-BLED & $3(3-4)$ \\
\hline \multicolumn{2}{|l|}{ Procedure indication } \\
\hline Gastrointestinal haemorrhage & $51(30.5 \%)$ \\
\hline Cranial haemorrhage & $38(22.8 \%)$ \\
\hline Other haemorrhages & $28(16.8 \%)$ \\
\hline CVA/embolism with OAC & $12(7.2 \%)$ \\
\hline High risk of bleeding & $7(4.2 \%)$ \\
\hline Others & $32(19.2 \%)$ \\
\hline Device size (lobe diameter ranging from 16 to 30 ) & $24(22-25)$ \\
\hline Need to change device* & $6(3.5 \%)$ \\
\hline Successful implantation & $158(94.6 \%)$ \\
\hline Procedural complications & $9(5.38 \%)$ \\
\hline TIA & $2(1.2 \%)$ \\
\hline Vascular complication & $4(2.39 \%)$ \\
\hline Cardiac tamponade & $2(1.2 \%)$ \\
\hline Device migration (percutaneously snared) & $1(0.6 \%)$ \\
\hline \multicolumn{2}{|c|}{$\begin{array}{l}\text { Values expressed as: number (percentage), mean } \pm \text { SD or median (25th-75th } \\
\text { percentiles). } \\
{ }^{*} \text { Three of the changes were due to a larger size, while the other three to a smaller } \\
\text { size. } \\
\text { CVA, cerebrovascular accident; HAS-BLED, hypertension, abnormal liver/renal function, } \\
\text { stroke history, bleeding predisposition, labile international normalised ratios, elderly, } \\
\text { drugs/alcohol use; OAC, oral anticoagulant; TIA, transient ischaemic attack. }\end{array}$} \\
\hline
\end{tabular}

subjects, $5.7 \%$ major and $4.4 \%$ relevant without meeting major criteria, and $4.4 \%$ suffered stroke. Findings from echocardiography controls are also shown in table 2 . In all, 13 minimal periprosthetic leaks were detected that did not meet the $<3 \mathrm{~mm}$ significance criterion, together with 18 cases of minimal small atrial septal defect shunts (detected by the existence of flowpassage through the interatrial septum by eco-colour Doppler examination), which gradually disappeared on subsequent controls.

Table 3 shows observed events and $\mathrm{CHADS}_{2}, \mathrm{CHA}_{2} \mathrm{DS}_{2}$-VASc and HAS-BLED-predicted events at 12 and 24 months (expressed as annual event rates, 290 patients/year).

Significant differences in stroke events were observed during the first year, whereas major bleeding events were only observed during the second year. Tables 4 and 5, respectively, show the comparative reduction in stroke following LAA occlusion,

Table 2 Raw clinical events and echocardiographic findings during follow-up in 158 successfully implanted patients

\begin{tabular}{lc}
\hline Clinical events & \\
Death & $17(10.8 \%)$ \\
Major bleeding & $9(5.7 \%)$ \\
Minor relevant bleeding & $7(4.4 \%)$ \\
Total bleeding events & $16(10.1 \%)$ \\
Stroke/TIA & $7(4.4 \%)$ \\
Some event & $30(19.0 \%)$ \\
Echocardiographic findings & $13(8.2 \%)$ \\
Device thrombus & $18(11.4 \%)$ \\
Small residual ASD & $13(8.2 \%)$ \\
Leak & \\
\hline ASD, atrial septal defect; TIA, transient ischaemic attack.
\end{tabular}

contrary to the $\mathrm{CHADS}_{2}$ score expected rate, and the types of haemorrhage occurring over follow-up, mainly gastrointestinal. Figure 1 shows the Kaplan-Meier event-free survival curve.

Table 6 shows the percentage of patients under dual platelet therapy and/or at least one antiaggregant treatment at 12 and 24 months of follow-up.

\section{DISCUSSION}

This study in LAA occlusion with an occlusion device is one of only three similar studies (together with the European ACP registry and the ASAP with Watchman study) with over 150 patients contraindicated for OACs, and has one of the longest follow-up periods. ${ }^{12} 13$

The main finding is that the reduction in the rate of events such as stroke or bleeding versus the score-predicted rate in this patient group ${ }^{6-9}$ is significant as of the first and second year postimplantation, respectively.

\section{Reduction of expected events during follow-up}

In the first year, significant difference between observed and $\mathrm{CHADS}_{2}$-predicted stroke and TIA rate was observed despite peri-implantation events and possible thrombus formation on the devices in the first few months. Incidence, therefore, was $3.9 \%$ (or 5.2\% including peri-implantation events) versus $9.6 \%$ expected rate. Nevertheless, at 2 years when expressed as annual event rates, 290 patients/year, this was $2.4 \%$ versus $9.6 \%$ scorepredicted rate $(\mathrm{p}<0.001)$.

In the ASAP study, all-cause stroke or systemic embolism occurred in four patients $(2.3 \%$ per year): ischaemic stroke in three patients $(1.7 \%$ per year) and haemorrhagic stroke in one patient $\left(0.6 \%\right.$ per year). ${ }^{13}$ In other series, stroke and TIAs are usually separated, but in general the approximate mean percentage of stroke/TIA ranged from $2 \%$ to $3 \%$ per year, a $70 \%$ reduction with respect to the score-predicted rate (table 4). ${ }^{2} 12$ 14-19

Thrombus formation on the device usually occurs around the delivery cable attaching screw, but improvements in design and implantation techniques (faster, $100 \mathrm{U} / \mathrm{kg}$ heparin following transseptal puncture, activated clotting time (ACT) monitoring) will probably reduce incidence of thrombi. Most of them are located over the upper quadrant between the screw and the left lateral ridge; they are not usually greater than $5-10 \mathrm{~mm}$ and respond well to treatment with low molecular weight heparins for 2 weeks. Once the device is endocardiolised, thrombus formation is virtually nil.

In this series, thrombus formation on the device occurred in around $8 \%$ of patients, similar to other studies where it ranges from $5 \%$ to $17 \%$ depending on the strictness and definition of the TOE follow-up protocol (inclusion/exclusion of mural thrombus). ${ }^{5}$ 12-19 More importantly, thrombus rate is higher when dual antiplatelet therapy (DAPT) is withdrawn in the first 2 months, and usually falls with the addition of a 2-3-week course of enoxaparin. ${ }^{1418} 19$ Nevertheless, information on postimplantation antithrombotic therapy is somewhat contradictory. In the PROTECT AF study in the Watchman device, ${ }^{2}$ warfarin was administered for the first 45 days, followed by DAPT. In other studies, DAPT is administered for 3 months, followed by a further 3 months with ASA alone, ${ }^{14-17} 19$ while others report good results with DAPT for only 6 weeks, following by indefinite ASA $^{18}$ suggesting that DAPT is more effective than acenocoumarol or warfarin. ${ }^{18}$

One of the most interesting findings in this series is the reduced incidence of bleeding, which was significant between the first and second years following withdrawal of antiplatelet drugs. Bleeding at 2 years was $10.4 \%$ (16 patients), of which 
Table 3 Observed versus expected events at 12- and 24-month follow-up, adjusted for patient/year

\begin{tabular}{|c|c|c|c|c|c|c|}
\hline \multirow[b]{2}{*}{ Events } & \multicolumn{3}{|c|}{ 12-month (158 patients/year) } & \multicolumn{3}{|c|}{$\begin{array}{l}\text { Global follow-up (annual event rates, } \\
290 \text { patients/year) }\end{array}$} \\
\hline & Observed & Expected* & $\mathrm{p}$ Value & Observed & Expected* & $\mathrm{p}$ Value \\
\hline Major bleeding & $8(5.2 \%)$ & $\begin{array}{l}6.6 \% \\
\text { HAS-BLED }\end{array}$ & 0.400 & $9(3.1 \%)$ & $\begin{array}{l}6.6 \% \\
\text { HAS-BLED }\end{array}$ & 0.047 \\
\hline Total bleeding (major+relevant) & $15(9.5 \%)$ & & & $16(5.5 \%)$ & & \\
\hline Stroke/TIA & & $8.3 \% \mathrm{CHA}_{2} \mathrm{DS}_{2}$-VASC & 0.025 & & $8.3 \% \mathrm{CHA}_{2} \mathrm{DS}_{2}$-VASC & 0.003 \\
\hline
\end{tabular}

$4.4 \%$ were relevant (minor) (seven patients) and 5.7\% major (nine patients) versus a HAS-BLED-predicted rate of $6.6 \%$ major bleeding events (NS). This is to be expected since during the first 6 months patients were given antiplatelet agents, and the BAFTA and ACTIVE studies have shown that bleeding with antiplatelet drugs is equivalent to bleeding with OAC, particularly among elderly patients. ${ }^{20}{ }^{21}$ Nevertheless, in the second year, when most patients no longer took antiplatelet drugs, the bleeding rate in this series (when expressed as annual event rates, 290 patients/year) remained practically unchanged $(3.1 \%$ vs HAS-BLED-predicted $6.6 \%(p=0.047))$. These findings are wholly consistent with the longer follow-up period of the PROTECT AF study, in which the balance of events in favour of the implant was more noticeable during the second year. ${ }^{3}$

Relevant bleeding events are not usually shown when reporting major bleeding, which is on average 3\%-3.6\% versus minor relevant bleeding, with an annual rate that can exceed $10 \%{ }^{1}$ Lack of information leads to underestimation of the percentage of patients requiring suspension of therapy and the effect this can have. This is very important since real-life studies that include patients who would otherwise be excluded from randomised series have shown that in follow-up of less than 2 years, up to $51.4 \%$ of patients had to suspend anticoagulant therapy due to intercurrent conditions (procedures, falls, etc) or haemorrhagic complications (34\%), 22 incidence of the latter being higher with higher $\mathrm{CHADS}_{2}$ and HAS-BLED scores. These studies showed that the risk of stroke during suspension periods increased $(\mathrm{OR}=1.60)^{22} 23$ and in the ROCKET AF study, the risk of thromboembolic events during suspension was more than $6 \%-8 \% .{ }^{24}$ Suspension after 2 years is due to bleeding problems and poor compliance. In the PROTECT AF study, for example, $16 \%$ did not resume warfarin after 2 years, ${ }^{3}$ and the situation is no better with new OACs, as shown by the $21 \%$ rate reported in the RELY study in dabigatran.

Furthermore, the fact that studies in LAA occlusion devices usually include patients contraindicated for OACs and that the annual rate of major bleeding in patients not included in randomised studies ${ }^{25}$ is closer to $7 \%$ than the $3 \%-3.6 \%$ found in these studies is widely ignored. In a review of 994 patients treated with warfarin with some kind of bleeding, less than $70 \%$ would have been eligible for a clinical trial, and the risk of bleeding increases dramatically with more exclusion criteria. ${ }^{26}$

Most bleeding observed during follow-up in this series was gastrointestinal. Approximately 58\% of bleeding with dabigatran was gastrointestinal, and incidence was higher than with warfarin $(p<0.001) .{ }^{27}$ Annual incidence of gastrointestinal bleeding is around $4.5 \%$ in patients taking OAC. ${ }^{28}$ Resumption of warfarin leads to bleeding recurrence at 3 months as high as $10 \%$, and even $5.5 \%$ without resumption. ${ }^{28}$ The 30 -day mortality rate following major bleeding due to OAC is significant, ranging from $9.1 \%$ to $13 \% .^{27}$

\section{Procedural safety}

Safety events have fallen to less than half the rate reported in the PROTECT AF study and Continued Access Protocol register, the European ACP register and postmarket

Table 4 Observed and expected events at 1 year in different studies in LAA occlusion patients contraindicated for OAC

\begin{tabular}{|c|c|c|c|c|c|c|c|c|}
\hline Study name & $\begin{array}{l}\text { Number of } \\
\text { patients }\end{array}$ & $\mathrm{CHA}_{2} \mathrm{DS}_{2}$-VASc & $\begin{array}{l}\text { Follow-up } \\
\text { (months) }\end{array}$ & $\begin{array}{l}\text { Total stroke/TIA } \\
\text { follow-up }\end{array}$ & Stroke \%/year & $\begin{array}{l}\% \\
\text { Reduction }\end{array}$ & $\begin{array}{l}\text { Death } \\
\text { patient/ } \\
\text { year }\end{array}$ & $\begin{array}{l}\text { Antithrombotic } \\
\text { therapy }\end{array}$ \\
\hline $\begin{array}{l}\text { Spanish Unicentre } \\
(\mathrm{ACP})^{14}\end{array}$ & 35 & $3.94 \pm 1.89$ & $21.14 \pm 10.1$ & $2.85 \%(1 / 35)$ & $0 \%$ versus $5.45 \%$ & & $5.04 \%$ & $\begin{array}{l}3-6 \text { m DAPT } \\
3 \text { m indefinite ASA }\end{array}$ \\
\hline $\begin{array}{l}\text { Partial ACP European } \\
\text { postmarket }\end{array}$ & 145 & $3.7 \pm 1.7$ & 24 & $2.12 \%(1 / 47)$ & $\begin{array}{l}1.24 \% \text { versus } \\
5.33 \%\end{array}$ & $65 \%$ & NA & $3 \mathrm{~m}$ DAPT $3 \mathrm{~m}$ ASA \\
\hline $\begin{array}{l}\text { USA-European } \\
\text { ASAP (Watch) }\end{array}$ & 150 & $4.4 \pm 1.7$ & $14.4 \pm 8.6$ & $2.6 \%(4 / 150)$ & $1.7 \%$ vs $7.3 \%$ & $77 \%$ & $5 \%$ & $6 \mathrm{~m}$ DAPT \\
\hline Canadian $(\mathrm{ACP})^{15}$ & 52 & $5(4-6)$ & $20 \pm 5$ & $5.7 \%(3 / 52)$ & $1.1 \%$ vs $8.6 \%$ & $87 \%$ & $5.8 \%$ & $1-3$ or $1-6 m$ \\
\hline $\begin{array}{l}\text { Iberian multicentre } \\
\text { (current) }\end{array}$ & 167 & $4(3-6)$ & $22 \pm 8.3$ & $4.2 \%(7 / 167)$ & $2.4 \%$ vs $9.6 \%$ & $75 \%$ & $5.8 \%$ & $\begin{array}{l}3-6 \mathrm{~m} \text { DAPT } \\
6 \mathrm{~m} \text { indefinite ASA }\end{array}$ \\
\hline $\begin{array}{l}\text { Average of figures or } \\
\text { percentages }\end{array}$ & 549 & 4.2 & 20.38 & $3.54 \%(16 / 451)$ & $1.28 \%$ vs $7.25 \%$ & $76 \%$ & $5.41 \%$ & \\
\hline
\end{tabular}


Table 5 Details of major bleeding over follow-up

\begin{tabular}{|c|c|c|c|c|c|c|c|}
\hline & Type of haemorrhage & Reason for implantation & Gender & Age & HAS-BLED & Time since implantation (months) & Treatment \\
\hline 1 & Upper gastrointestinal bleeding & Gastrointestinal haemorrhage & $\mathrm{F}$ & 68 & 3 & 3 & ASA and clopidogrel \\
\hline 2 & Upper gastrointestinal bleeding & Gastrointestinal haemorrhage & $\mathrm{F}$ & 78 & 4 & 24 & ASA and clopidogrel \\
\hline 3 & Cerebral haematoma & Cerebral haemorrhage & M & 73 & 3 & 6 & ASA \\
\hline 4 & Upper gastrointestinal bleeding & Ischaemic CVA & M & 73 & 4 & 3 & ASA \\
\hline 5 & Lower gastrointestinal bleeding & Lower gastrointestinal bleeding & M & 83 & 3 & 6 & ASA and clopidogrel \\
\hline 6 & Lower gastrointestinal bleeding & Lower gastrointestinal bleeding & M & 70 & 4 & 12 & Nothing \\
\hline 7 & Lower gastrointestinal bleeding & Severe anaemia & $\mathrm{F}$ & 78 & 4 & 12 & ASA \\
\hline 8 & Lower gastrointestinal bleeding & Lower gastrointestinal bleeding & M & 84 & 4 & 3 & ASA and clopidogrel \\
\hline 9 & Lower gastrointestinal bleeding & Lower gastrointestinal bleeding & $M$ & 65 & 4 & 1 & ASA and clopidogrel \\
\hline
\end{tabular}

surveillance. $^{29} 30$ However, recent studies in populations similar to this series in highly experienced hospitals continue to report rates of between $4 \%$ and $8 \%$. The ASAP and the Canadian study reported $8.7 \%$ and $5.8 \%$, respectively, although most events were resolved with few sequelae or none at all. ${ }^{13}{ }^{15} \mathrm{~A}$ complication rate of around $5.38 \%$ is average. Vascular complications in most studies range from $1 \%$ to $2.5 \%$. For example, the ASAP study reported $2 \%$ vascular problems and $3.8 \%$ major bleeding due to haematoma at the puncture site, while other events such as $1.2 \%$ perioperative TIA, 1\%-2\% cardiac tamponade and $0.6 \%$ device migration are at the lower end of the rates reported in leading studies. The authors believe that after accidental puncture of the femoral artery the needle should not be withdrawn and compression applied immediately, but rather the introducer should remain in the artery and compression or percutaneous closure performed at the end of the procedure as programmed as otherwise arteriovenous haematomas and/or fistulas can form.
Regarding study limitations, this study recruited 167 patients from 12 hospitals, thereby including patients from hospitals with varying experience in the procedure. Nevertheless, most sites started and included cases under a common monitor, a factor that the authors believe ensures homogeneity. Instead of being randomised, event comparison is score-based; however, the scores used have been thoroughly validated in the literature. Finally, the methodological approach applied during the follow-up period could have been more exhaustive than that used in routine practice and in highly experienced groups. ${ }^{17}$

In conclusion, these findings show that LAA closure with an occlusion device in patients contraindicated for OAC is a reasonably safe therapeutic option associated with fewer thromboembolic and haemorrhagic events than those expected from risk scores, particularly after the first year postimplantation following endothelialisation and withdrawal of antiplatelet therapy.

New studies with longer follow-up periods and early discontinuation of DAPT would be of great interest to verify whether
Figure 1 Kaplan-Meier event-free survival curves over 24-month follow-up.

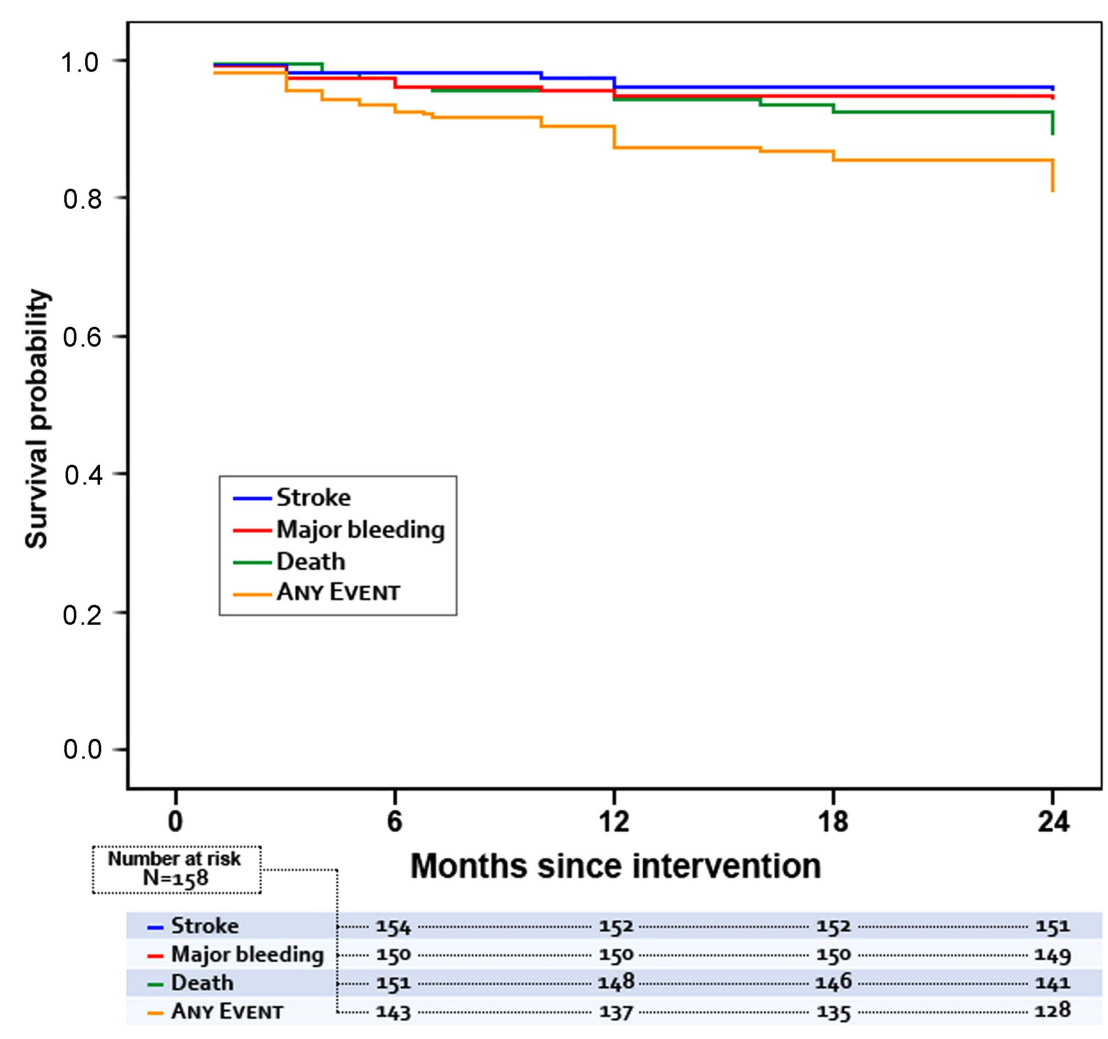


Table 6 Percentage of patients under DAPT and/or at least one antiaggregant treatment at 12 and 24 months of follow-up

\begin{tabular}{lcccr}
\hline & Discharge & 1 month & 6 months & 12 months \\
\hline Patients & $158(100 \%)$ & $157(100 \%)$ & $151(100 \%)$ & $148(100 \%)$ \\
No APT & $1(0.6 \%)$ & $1(0.6 \%)$ & $1(0.7 \%)$ & $5(3.4 \%)$ \\
Only ASA or & $14(8.9 \%)$ & $26(16.6 \%)$ & $111(73.5 \%)$ & $130(87.8 \%)$ \\
clopidogrel & & & & \\
DAPT & $138(87.3 \%)$ & $128(81.5 \%)$ & $33(21.9 \%)$ & $7(4.7 \%)$ \\
OAC & $5(3.2 \%)$ & $2(1.3 \%)$ & $6(3.9 \%)$ & $6(4.1 \%)$ \\
\hline
\end{tabular}

APT, antiplatelet therapy; ASA, aspirin; DAPT, dual antiplatelet therapy; OAC, oral anticoagulation.

bleeding events during the first year are reduced without losing the efficacy of lowering thromboembolic events. This could broaden current indications.

\section{Key messages}

\section{What is already known on this subject?}

Left atrial appendage closure has been shown not to be inferior to oral anticoagulants (OACs) in the treatment of patients with non-valvular atrial fibrillation, and some studies suggest it could be a good alternative for patients contraindicated for OACs due to high risk of haemorrhage.

\section{What might this study add?}

The reduction of events in this population with respect to expected outcomes based on risk scores is significant in the first year for stroke (53\% at 12 months and $73 \%$ at 24 months) and in the second year for haemorrhage (53\%).

\section{How might this impact on clinical practice?}

Left atrial appendage closure is shown to be an effective treatment for patients contraindicated for OACs. However, with current antithrombotic therapy similar haemorrhagic complications can occur in the first year, suggesting the need to seek alternative antithrombotic treatment and maximise vigilance for this complication during this period.

\author{
Author affiliations \\ ${ }^{1}$ Hospital Universitario Infanta Cristina, Badajoz, Spain \\ ${ }^{2}$ Hospital de Coimbra, Coimbra, Portugal \\ ${ }^{3}$ Hospital Universitario de Salamanca, Salamanca, Spain \\ ${ }^{4}$ Hospital Clínico Universitario de Valladolid, Valladolid, Spain \\ ${ }^{5}$ Hospital Puerta de Hierro, Majadahonda, Spain \\ ${ }^{6}$ Hospital Clínic de Barcelona, Barcelona, Spain \\ ${ }^{7}$ Hospital Universitario La Paz, Madrid, Spain \\ ${ }^{8}$ Hospital Virgen de la Victoria, Málaga, Spain \\ ${ }^{9}$ Hospital de La Princesa, Madrid, Spain \\ ${ }^{10}$ Hospital de Burgos, Burgos, Spain \\ ${ }^{11}$ Hospital 12 de Octubre, Madrid, Spain \\ ${ }^{12}$ Hospital de Oporto, Oporto, Portugal
}

Acknowledgements Data analysis was performed by the Statistical Department of Extremadura University.

Twitter Follow Jesús Herrero-Garibi at @jesusgaribi

Contributors All authors contributed equally to study design, patient selection and surgical procedures in their respective hospitals, and data acquisition for the Registry. The manuscript was drafted by JRLM. All authors revised the drafts and approved the final version.

Competing interests The authors declare no conflicts of interest, except for three of them: JRLM, ICG and VGR who are proctors for LAA closure with ACP and receive minimal economic compensation for this activity.

\section{Patient consent Obtained.}

Ethics approval Independent ethics committees of contributing hospitals.

Provenance and peer review Not commissioned; externally peer reviewed.

\section{REFERENCES}

1 Ruff CT, Giugliano RP, Braunwald E, et al. Comparison of the efficacy and safety of new oral anticoagulants with warfarin in patients with atrial fibrillation: a meta-analysis of randomised trials. Lancet 2014;383:955-62.

2 Holmes DR, Reddy VY, Turi ZG, et al. Percutaneous closure of the left atrial appendage versus warfarin therapy for prevention of stroke in patients with atrial fibrillation: a randomised non-inferiority trial. Lancet 2009;374:534-42.

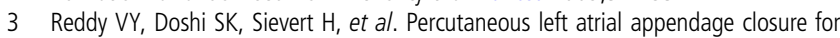
stroke prophylaxis in patients with atrial fibrillation: 2.3-Year Follow-up of the PROTECT AF (Watchman Left Atrial Appendage System for Embolic Protection in Patients with Atrial Fibrillation) Trial. Circulation 2013;127:720-9.

4 Gangireddy SR, Halperin JL, Fuster V, et al. Percutaneous left atrial appendage closure for stroke prevention in patients with atrial fibrillation: an assessment of net clinical benefit. Eur Heart J 2012;33:2700-8.

5 Camm AJ, Lip GY, De Caterina R, et al. 2012 focused update of the ESC Guidelines for the management of atrial fibrillation: an update of the 2010 ESC Guidelines for the management of atrial fibrillation. Developed with the special contribution of the European Heart Rhythm Association. Eur Heart J 2012;33:2719-47.

6 Gage BF, van Walraven C, Pearce L, et al. Selecting patients with atrial fibrillation for anticoagulation: stroke risk stratification in patients taking aspirin. Circulation 2004; 110:2287-92.

7 Coppens M, Eikelboom JW, Hart RG, et al. The CHA2DS2-VASc score identifies those patients with atrial fibrillation and a CHADS2 score of 1 who are unlikely to benefit from oral anticoagulant therapy. Eur Heart J 2013;34:170-6.

8 Pisters R, Lane DA, Nieuwlaat R, et al. A novel user-friendly score (HAS-BLED) to assess 1-year risk of major bleeding in patients with atrial fibrillation: the Euro Heart Survey. Chest 2010;138:1093-100.

9 Friberg L, Rosenqvist M, Lip GY. Evaluation of risk stratification schemes for ischaemic stroke and bleeding in 182678 patients with atrial fibrillation: the Swedish Atrial Fibrillation cohort study. Eur Heart J 2012;33:1500-10.

10 Schulman S, Angeras U, Bergqvist D, et al. Definition of major bleeding in clinical investigations of antihemostatic medicinal products in surgical patients. J Thromb Haemost 2010;8:202-4.

11 Leon MB, Piazza N, Nikolsky E, et al. Standardized endpoint definitions for Transcatheter Aortic Valve Implantation clinical trials: a consensus report from the Valve Academic Research Consortium. J Am Coll Cardiol 2011;57:253-69.

12 Park JW, Bethencourt A, Sievert $H$, et al. Left atrial appendage closure with Amplatzer cardiac plug in atrial fibrillation: initial European experience. Catheter Cardiovasc Interv 2011;77:700-6.

13 Reddy VY, Mobius-Winkler S, Miller MA, et al. Left atrial appendage closure with the Watchman device in patients with a contraindication for oral anticoagulation: the ASAP study (ASA Plavix Feasibility Study With Watchman Left Atrial Appendage Closure Technology). J Am Coll Cardiol 2013;61:2551-6.

14 Lopez-Minguez JR, Eldoayen-Gragera J, Gonzalez-Fernandez R, et al. Immediate and one-year results in 35 consecutive patients after closure of left atrial appendage with the Amplatzer cardiac plug. Rev Esp Cardiol 2013;66:90-7.

15 Urena M, Rodes-Cabau J, Freixa X, et al. Percutaneous left atrial appendage closure with the AMPLATZER cardiac plug device in patients with nonvalvular atrial fibrillation and contraindications to anticoagulation therapy. J Am Coll Cardiol 2013;62:96-102.

16 Meincke F, Schmidt-Salzmann M, Kreidel F, et al. New technical and anticoagulation aspects for left atrial appendage closure using the WATCHMAN(R) device in patients not taking warfarin. Eurolntervention 2013;9:463-8.

17 Nietlispach F, Gloekler S, Krause R, et al. Amplatzer left atrial appendage occlusion: single center 10-year experience. Catheter Cardiovasc Interv 2013;82:283-9.

18 Chun KR, Bordignon S, Urban V, et al. Left atrial appendage closure followed by 6 weeks of antithrombotic therapy: a prospective single-center experience. Heart Rhythm 2013;10:1792-9.

19 Plicht B, Konorza TF, Kahlert $\mathrm{P}$, et al. Risk factors for thrombus formation on the Amplatzer cardiac plug after left atrial appendage occlusion. JACC Cardiovasc Interv 2013;6:606-13

20 Mant J, Hobbs FD, Fletcher K, et al. Warfarin versus aspirin for stroke prevention in an elderly community population with atrial fibrillation (the Birmingham Atrial Fibrillation Treatment of the Aged Study, BAFTA): a randomised controlled trial. Lancet 2007;370:493-503.

21 Connolly SJ, Pogue J, Hart RG, et al. Effect of clopidogrel added to aspirin in patients with atrial fibrillation. N Engl J Med 2009;360:2066-78.

22 Deitelzweig SB, Pinsky B, Buysman $E$, et al. Bleeding as an outcome among patients with nonvalvular atrial fibrillation in a large managed care population. Clin Ther 2013;35:1536-45 e1.

23 Deitelzweig SB, Buysman E, Pinsky B, et al. Warfarin use and stroke risk among patients with nonvalvular atrial fibrillation in a large managed care population. Clin Ther 2013;35:1201-10. 
24 Patel MR, Hellkamp AS, Lokhnygina $Y$, et al. Outcomes of discontinuing rivaroxaban compared with warfarin in patients with nonvalvular atrial fibrillation: analysis from the ROCKET AF trial (Rivaroxaban Once-Daily, Oral, Direct Factor Xa Inhibition Compared With Vitamin K Antagonism for Prevention of Stroke and Embolism Trial in Atrial Fibrillation). J Am Coll Cardiol 2013;61:651-8.

25 Pengo V, Legnani C, Noventa F, et al. Oral anticoagulant therapy in patients with nonrheumatic atrial fibrillation and risk of bleeding. A Multicenter Inception Cohort Study. Thromb Haemost 2001;85:418-22.

26 Levi M, Hovingh K. Bleeding complications in patients on anticoagulants who would have been disqualified for clinical trials. Thromb Haemost 2008;100:1047-51.
27 Majeed A, Hwang HG, Connolly SJ, et al. Management and outcomes of major bleeding during treatment with dabigatran or warfarin. Circulation 2013;128:2325-32.

28 Witt DM, Delate T, Garcia DA, et al. Risk of thromboembolism, recurrent hemorrhage, and death after warfarin therapy interruption for gastrointestinal tract bleeding. Arch Intern Med 2012;172:1484-91.

29 Reddy VY, Holmes D, Doshi SK, et al. Safety of percutaneous left atrial appendage closure: results from the Watchman Left Atrial Appendage System for Embolic Protection in Patients with AF (PROTECT AF) clinical trial and the Continued Access Registry. Circulation 2011;123:417-24.

30 Park JW, Sievert $\mathrm{H}$, Schillinger W, et al. Interim data from AMPLATZER cardiac plug registry [Abstract]. J Am Coll Cardiol 2011;58:Abstract TCT-112. 